\title{
INFLUENCIA DO PROGRAMA NACIONAL DE ACESSO AO ENSINO TÉCNICO E EMPREGO - PRONATEC - NA FORMAÇÃO DO ALUNO DO ENSINO MÉDIO DAS ESCOLAS PÚBLICAS DE MARINGÁ - PARANÁ
}

Elizabete Neves Amorim*

Regiane da Silva Macuch**

RESUMO: O presente artigo pretende demonstrar a influência do Pronatec, na formação dos alunos das escolas Públicas da Rede Estadual de Ensino, especificamente da cidade de Maringá, como também, analisar quantitativamente o grau de satisfação dos alunos com os cursos ofertados. Também objetiva demonstrar as leis que norteiam este programa e as expectativas dos jovens com o termino do curso, suas possibilidades de empregabilidade, formas de oferta e benefícios aos alunos. Utilizou-se a pesquisa documental e bibliográfica, e para a pesquisa de campo o questionário para levantamento dos dados necessários para análise do programa. Chegou-se a conclusões positivas para as questões sociais referentes à oferta gratuita de cursos a uma população que certamente não poderia ter acesso a escolas de qualidade como as do sistema S. Por outro lado, demonstra a fragilidade da escola pública em preparar os alunos para uma formação humana e profissional de qualidade.

PALAVRAS-CHAVE: Políticas Públicas; Educação; Pronatec.

\section{INFLUENCE OF THE ACCESS PROGRAM TO TECHNICAL AND EMPLOYMENT TEACHING (PRONATEC) IN THE FORMATION OF HIGH SCHOOL STUDENTS IN MARINGÁ}

ABSTRACT: The influence of PRONATEC in the formation of students enrolled in government-run high schools in Maringá PR Brazil is investigated. Students' satisfaction note with regard to available courses is analyzed quantitatively. Laws foregrounding the program are analyzed, coupled to the young people's

\footnotetext{
"Núcleo de Educação do Paraná. E-mail: elizabete.neves@uol.com.br

* Docente no Programa de Pós-graduação em Promoção da Saúde do Centro e no Programa de Pósgraduação em Gestão do Conhecimento nas Organizações do Centro Universitário de Maringá (UNICESUMAR); Pesquisadora do Instituto Cesumar de Ciência, Tecnologia e Inovação (ICETI), Brasil.
} 
expectations at the end of the course, their possibility of employment, type of supply and students' benefits. Documentary and bibliographical research was employed and a questionnaire was set for data collection needed for the analysis. Results were positive with regard to the social issues on the free access to courses to a section of the population that otherwise it would not have any access to good S-type schools. On the other hand, the weakness of the public school in preparing students with the necessary human and professional formation was demonstrated.

KEY WORDS: Public policies; Education; Pronatec.

\section{INTRODUÇÃO}

A Educação Profissional é motivo de estudos de muitos educadores que buscam identificar a relação entre a experiência do trabalho e a educação. Muitos destes estudiosos acreditam que no trabalho, os homens criam e recriam sua própria existência (LUKÄCS,1978)

Estas discussões estão vinculadas as concepções de sociedade e de trabalho. "E neste embate de concepções de sociedade e trabalho que se insere a disputa pela educação como uma prática social mediadora do processo de produção, processo político, ideológico e cultural" (FRIGOTTO et al., 2005, p. 23).

A Secretaria Estadual de Educação - SEED - em sua Diretriz Curricular para a Educação Profissional, a partir de 2003 reassume a importância da Educação Profissional Politécnica, proposta na Lei de Diretrizes e Bases da Educação Nacional - LDBEN 9394/96, reafirmando uma concepção:

[...] que rompe com a dimensão que articula diretamente ao mercado e trabalho e a empregabilidade e laboral idade. Assume-se, também, o compromisso com a formação humana dos alunos, a qual requer apreensão dos conhecimentos científicos, tecnológicos e históricosociais pela via escolarizada, (PARANÁ, 2066, p. 20).

Em países onde o capitalismo impera são poucos os indivíduos com acesso a todos os níveis, formas e modalidades de ensino proposto na LDBEN n. 9394/96. A função social da escola que é a socialização do conhecimento fica restrita na condição 
de reprodutora ou transformadora das relações sociais impostas pela forma de produção da vida, ou seja, o trabalho. Neste sentido, na pesquisa de Lima e Pacheco (2017) é apontado que os pobres têm o seu direito a educação negado seja através do acesso à escola, permanência e/ou sucesso na mesma. Este processo faz parte do movimento histórico sócio econômico no qual a escola está inserida e muitas vezes condicionada. Os mesmos autores relatam o surgimento do Plano Nacional de Educação por meio da Conferência Nacional de Educação - CONAE que tinha como objetivo a construção deste Plano Nacional de Educação - PNL como política de Estado e não de governo. Este PNE tinha como proposta planejar a educação do país por 10 anos e eliminar as desigualdades educacionais existentes, "respeitando as particularidades e especificidades das populações visando a formação para o mundo do trabalho e exercício da cidadania”, Lima e Pacheco (2017, p. 495). Em suas metas o PNE promove a integração entre a Educação Básica e a Educação Profissional Técnica.

O Pronatec por sua vez, trata-se de uma política de governo, criado em 2011 com objetivo de fomentar a destinação de recursos públicos a entidades privadas definindo-se como um programa do Governo Federal constituindo-se como uma estratégia de governo para aumentar as matrículas de ensino técnico no país. $\mathrm{Na}$ pesquisa de Deitos, Lara e Zanardini (2015) é reforçada a ideia que a necessidade de aumento da força de trabalho influenciam a política educacional adotada no Pronatec. Neste sentido, reforçam que o aumento da escolarização nem sempre é requisito para empregabilidade e para a seleção da quantidade de força de trabalho necessárias a manutenção do stato quo proposto pelo capital.

É com decisiva determinação governamental que a educação é tomada como requisito indispensável ao processo de produção e desenvolvimento econômico, e como tal, a política educacional adotada traduz esses objetivos estratégicos e estruturantes (DEITOS; LARA; ZANARDINI, 2015, p. 989).

Como sempre acontece, o capital determina ações políticas para a educação e fomento de modalidades de ensino que venham atender os interesses do mercado. Como relatam os autores Deitos, Lara e Zanardini (2015), o volume e variedade dos cursos técnicos existentes no país, por meio dos cursos de qualificação, técnico e 
tecnológico atendem os aspectos qualitativos e quantitativos imediatos e mediatos para a formação da força de demandada pelo empresariado. Uma mostra desta força é o crescimento dos investimentos que, segundo os autores citados acima, passaram de 1,5 bilhões em 2006 para quase 6 bilhões de reais em 2011.

O Programa Nacional de Acesso ao Ensino Técnico e Emprego - Pronatec, entre outras intenções, busca garantir a formação e/ou qualificação técnica de profissionais que necessitam ingressar ou reingressar no mercado de trabalho, atendendo a uma necessidade social que é a geração de mão de obra qualificada para as atuais exigências do mercado de trabalho. Como previsto nas leis para a educação profissional técnica de nível médio, é necessário à promulgação de ferramentas que tornem o cidadão capaz de enfrentar as novas nuances propostas pelo mercado de trabalho. De acordo com o exposto, tem-se como questão se esta política pública governamental, voltada para uma necessidade histórica e empresarial, pode favorecer a vida dos estudantes que concluirão os cursos.

Esta fundamentação socioeconômica e política gera nos jovens e trabalhadores a internalizar que a sua qualificação escolar é uma condição para a boa empregabilidade.

Segundo Deitos, Lara e Zanardini (2015, p. 997), esses são condicionantes unilaterais para o jovem ingressar no meio profissional.

Como condição unilateral para o seu ingresso e permanência no processo produtivo (emprego e empregabilidade), e para a sua própria manutenção como força de trabalho, gerando internamente (nos indivíduos) as condições de aceitabilidade de expectativas sociais de desempenho escolar, qualificação e empregabilidade como condição unilateral à conquista de emprego no contexto econômico produtivo nacional, (DEITOS; LARA; ZANARDINI, 2015).

Enquanto a Educação Profissional, através dos cursos técnicos, referenciado pelo Catálogo Nacional de Cursos Técnicos, oferta uma formação na rede pública com gratuidade, o Pronatec eleva o número de matriculas priorizando um caráter privatista pagando uma bolsa formação ao aluno deste programa. Assim, o aluno da escola pública que frequenta aulas nos cursos técnicos, evade para se inscrever em cursos ofertados nas instituições de ensino particulares e que pagam esta bolsa. 
Esta ação fomenta "a principal política pública nacional de Educação Profissional e Tecnológica (EPT) da contemporaneidade", como dizem os autores Lima e Pacheco (2017, p. 490). Esses autores, indicam um breve histórico no Pronatec.

O PRONATEC, aprovado pela Lei $n^{0} 12.513$, de 26 de outubro de 2011, incorpora várias ações anteriores à sua criação e institui o Bolsa Formação, iniciativa que visa à qualificação e à habilitação de trabalhadores e estudantes brasileiros, constituindo foco de disputa pelos recursos públicos. Esse programa é responsável por mais de 8,1 milhões de matrículas em cursos de Educação Profissional Técnica de Nível Médio (EPTNM) e de Formação Inicial e Continuada (FIC) de 2011 a 2014. Sua abrangência ultrapassou o número de 4.300 municípios brasileiros, envolvendo 15 ministérios do governo Dilma Rousseff e as redes pública e privada, e o programa movimentou mais de $\mathrm{R} \$ 14$ bilhões no mesmo período, conforme informações disponibilizadas no sítio do Ministério de Educaçao - MEC, (LIMA; PACHECO, 2017, p. 491).

Este trabalho de pesquisa objetiva analisar e avaliar a influência do Programa Nacional de Acesso ao Ensino Técnico e Emprego - Pronatec como uma Política Pública governamental na formação do aluno do Ensino Médio da Educação Básica da Rede Pública Estadual de Ensino. Para chegar-se a este objetivo é necessário: identificar as leis que norteiam o Pronatec através de pesquisa bibliográfica, verificar a importância do Pronatec na Educação Formal dos alunos do Ensino Médio das escolas estaduais de Maringá no Estado do Paraná, relacionar quais os cursos ofertados no Pronatec geram maior interesse dos alunos, avaliar a importância Pronatec no processo de aprendizagem dos alunos do Ensino Médio e por fim diagnosticar o nível de satisfação dos alunos com o Programa enquanto Política Pública para a Educação no Estado do Paraná, especificamente para o município de Maringá. 


\section{FUNDAMENTAÇÃO TEÓRICA}

\subsection{O PRONATEC}

O Pronatec é um programa do Governo Federal que tem como objetivo oferecer cursos de Educação Profissional a estudantes, trabalhadores diversos, pessoas com deficiência e beneficiários dos programas federais de transferência de renda. A organização do programa constitui uma estratégia de governo, de política pública para aumentar as matrículas de ensino técnico no país integrando a qualificação profissional de trabalhadores com a elevação da sua escolaridade, constituindo-se em um instrumento de fomento ao desenvolvimento profissional, de inclusão e de promoção do exercício da cidadania.

O Pronatec - foi criado através da Lei 12.513 de 26 de outubro de 2011, cujo cabeçalho da Lei assim define sua especificidade:

Institui o Programa Nacional de Acesso ao Ensino Técnico e Emprego (Pronatec); altera as Leis $\mathrm{n}^{-} \mathbf{7 . 9 9 8}$, de 11 de janeiro de 1990, que regula o Programa do Seguro-Desemprego, o Abono Salarial e institui o Fundo de Amparo ao Trabalhador (FAT), n-8.212, de 24 de julho de 1991, que dispõe sobre a organização da Seguridade Social e institui Plano de Custeio, nํ⒑260, de 12 de julho de 2001, que dispõe sobre o Fundo de Financiamento ao Estudante do Ensino Superior, e nำ11.129, de 30 de junho de 2005, que institui o Programa Nacional de Inclusão de Jovens (ProJovem); e dá outras providências. (BRASIL, 2011).

Em seu artigo primeiro ressalta as finalidades de sua criação:

Art. 1 e É instituído o Programa Nacional de Acesso ao Ensino Técnico e Emprego (Pronatec), a ser executado pela União, com a finalidade de ampliar a oferta de Educação Profissional e Tecnológica, por meio de programas, projetos e ações de assistência técnica e financeira. (BRASIL, 2011).

O Pronatec como é um programa do Governo Federal em parceria com os Estados, pretende promover uma inovação e uma grande reforma na Educação 
Profissional. Com oferta de cursos de Qualificação denominados FIC - Formação Inicial Continuada e Curso Técnico na forma concomitante, oportuniza ao aluno, a partir do segundo ano do Ensino Médio, estudar regularmente o ensino Médio e ao mesmo tempo cursar um Curso Técnico no contra turno dos seus estudos formais.

Estes cursos não são ofertados de forma aleatória, os Cursos de Formação Inicial Continuada - FIC apresentam um total de 160 horas, sendo ofertados para alunos e trabalhadores e são editados pelo Ministério da Educação e norteados pelo Guia de Curos FIC. Este Guia é o instrumento de consolidação de uma Política Pública que visa aproximar o mercado de trabalho da Educação e do trabalhador. Diferentemente dos cursos FIC, os cursos Técnicos Concomitantes, também são ofertados seguindo o Catálogo Nacional de Cursos Técnicos, com duração de 800 horas, para alunos matriculados no Ensino Médio das escolas da Rede Pública de Educação.

Outra inovação garantida pelo Pronatec é a criação da Bolsa-Formação, onde a União financia os cursos presenciais para pessoas de diversos perfis, incluindo os alunos da Rede Pública Estadual. O Programa permite que a União financie o Curso, transporte, alimentação e materiais escolares a todos os beneficiários. Portanto, temos claro que o Pronatec sendo uma Política Pública governamental, atende uma grande quantidade de pessoas que estão inseridas em outras secretarias como: Seguridade Social, Ministério do Desenvolvimento Social - MDS, Assistência Social, entre outras.

A bolsa-formação atenderá tanto os Cursos Técnicos, como também, os cursos de curta duração denominados cursos FIC. Assim, o Pronatec tem em rede Federal, segundo o GUIA Pronatec, os seguintes objetivos:

1. Expandir, interiorizar e democratizar a oferta presencial e a distância de Cursos Técnicos e de Formação Inicial e Continuada (FIC);

2. Fomentar e apoiar a expansão da rede física de atendimento da Educação Profissional e Tecnológica - EPT;

3. Contribuir para a melhoria da qualidade do ensino médio público, por meio da articulação com a educação profissional;

4. Ampliar as oportunidades educacionais dos trabalhadores por meio do incremento da formação e qualificação profissional; 
5. Estimular a difusão de recursos pedagógicos para apoiar a oferta de cursos de EPT.

\subsection{A EDUCAÇÃO PROFISSIONALNO ESTADO DO PARANÁ}

A educação profissional de nível médio no Estado do Paraná é orientada pela Diretriz Curricular da Educação Profissional que em seus fundamentos Políticos e Pedagógicos contemplam: defesa da educação como direito de todos os cidadãos; valorização dos profissionais da educação; garantia de escola pública, gratuita e de qualidade; atendimento à diversidade cultural; gestão escolar democrática, participativa e colegiada.

A aplicação destes princípios se pauta na dimensão teórico-metodológica a seguir:

Quadro 1. Educação Profissional de Nível Médio: dimensões teórico-metodológicas

\begin{tabular}{|l|}
\hline Tomar o trabalho como princípio educativo; \\
\hline Integrar conhecimentos básico e aplicado; \\
\hline Relacionar teoria e prática, parte e totalidade; \\
\hline Integrar as dimensões disciplinar e interdisciplinar; \\
\hline Contemplar os conteúdos e habilidades da área de comunicação; \\
\hline Integrar os conteúdos e habilidades da área de comunicação; \\
\hline Integrar os conteúdos sócio-históricos aos científicos e tecnológicos; \\
\hline Contemplar os conteúdos culturais a partir das relações entre ciência, cultura e sociedade. \\
\hline
\end{tabular}

Fonte: Secretaria de Estado da Educação - SEED

Pautados nas Diretrizes para a Educação Profissional de Nível Médio, o Estado do Paraná, em seu plano de metas da Secretaria de Estado da Educação - SEED para a Educação Profissional, objetiva criar incentivos e alternativas educacionais de inserção e permanência dos alunos nos curso técnicos, adere ao Pronatec do Governo Federal.

O Pronatec tem como objetivo expandir, interiorizar e democratizar a oferta de cursos técnicos, na forma concomitante em nível médio onde o aluno 
realiza um curso técnico enquanto cursa o Ensino Médio, e também cursos na forma de Formação Inicial e Continuada - FIC, que são cursos de qualificação, para trabalhadores e também para os alunos do Ensino Médio da Rede Pública Estadual.

Os cursos de Formação Inicial - FIC serão ofertados gratuitamente, pelas instituições parceiras: Instituto Federal do Paraná - IFPR; Serviço Nacional de Aprendizagem Industrial do Paraná - Senai e Serviço Nacional de Aprendizagem Comercial do Paraná - Senac.

A Rede de Instituições Públicas do Paraná promove as seguintes ações para esta parceria com o Pronatec:

- Divulgar nas escolas da rede pública estadual que ofertam Ensino Médio os cursos e vagas oferecidos pelas instituições parceiras;

- Definir a escola POLO (unidade demandante) da rede pública estadual, no município de oferta de cursos, que será responsável pelas inscrições, seleção e pré-matrícula dos beneficiários;

- Indicar o supervisor de demanda que deverá ser um servidor do Quadro Próprio do Magistério - QPM que tenha conhecimento da proposta e legislação da Educação Profissional.

- Realizar a habilitação do responsável pelo órgão supervisor de demanda no Sistema de Segurança Digital - SSD (manual de operações do Pronatec)

- Cadastrar a unidade demandante no Sistema Nacional de Informações da Educação Profissional e Tecnológica - Sistec/MEC (manual de operações do Pronatec);

- Orientar a unidade demandante na realização da sua habilitação no SSD (manual de operações do Pronatec);

- Orientar, acompanhar e supervisionar as ações da Unidade demandante.

- Encaminhar às instituições parceiras a relação dos selecionados.

\subsection{PARCEIROS DO PRONATEC QUE ATUAM COMO OFERTANTES DOS CURSOS}

Para oferta dos cursos, o Pronatec conta com parceiros como o Ministério da Educação, Secretaria de Estado da Educação do Paraná, Departamento de Educação 
e Trabalho Instituto Federal do Paraná, Serviço Nacional de Aprendizagem Industrial do Paraná - Senai, Serviço Nacional de Aprendizagem Comercial do Paraná - Senac, viabilizando as ações necessárias à esta política.

\subsection{EFETIVAÇÃO DO PROGRAMA PRONATEC NAS ESCOLAS PÚBLICAS}

O desenvolvimento das ações do Pronatec nas escolas da Rede Pública Estadual não ocorre de maneira desorganizada e aleatória. Envolvem todos os profissionais da Educação que atuam dentro da escola. Os pedagogos, responsáveis pelas ações pedagógicas da escola assumem a função de divulgar os cursos, orientando os alunos sobre o tipo de perfil do curso oferecido.

Portanto, a escola enquanto mediadora de todo processo de aprendizagem, tem no Pronatec um apoio para oportunizar aos alunos uma Educação Técnica formal, com vias ao acesso ao mercado de trabalho. Muito embora, as escolas da Rede Estadual Pública do Paraná também ofertem cursos Técnicos, estes não conflitam com o Pronatec, pois há uma preocupação por parte da SEED escolas e parceiros em não ofertar os mesmos cursos, ampliando assim, as oportunidades e o leque de opções que o aluno e o trabalhador tem de escolha.

O Programa é avaliado em proporções qualitativas, através do manual de Organização do Trabalho Pedagógico - ODP. O processo de acompanhamento pedagógico dos alunos do Ensino Médio ou da modalidade Educação de Jovens e Adultos - EJA, que cursam a forma concomitante, tem o objetivo de favorecer a permanência e a conclusão da última etapa da educação básica, como também o curso da Educação Profissional com qualidade e êxito, possibilitando a inserção e permanência no mundo do trabalho.

A Organização do Trabalho Pedagógico - ODP do Pronatec avalia a Frequência, o Aproveitamento, e as Dificuldades de Aprendizagem dos alunos. Todo o acompanhamento do Pronatec é feito por dois Manuais denominado Manual de Operação do Programa Nacional de Acesso ao Ensino Técnico e Emprego interligado com o Sistema de Informações da Educação Profissional e Tecnológica - Sistec. Este manual é dividido em dois módulos. O Módulo 1 descreve e norteia o cadastramento de Parceiros Demandantes, de Supervisores de Demanda e de 
Unidades Demandantes. Já o Módulo 2 descreve e norteia o cadastramento de turmas e de pré-matrícula. A matrícula dos alunos classificados para o Pronatec fica a cargo dos parceiros.

\subsection{PARCEIROS DO PRONATEC EM MARINGÁ}

Em Maringá o Pronatec é realizado com dois parceiros, pois são os únicos que possuem instalações na cidade. São eles: o Senac que oferta cursos voltados para a área de Gestão Comercial e o Senai para a área da Indústria. Estas instituições visam o andamento do Programa com vistas ao processo de ensino aprendizagem dos alunos, ofertando condições físicas, materiais e tecnológicas para o desenvolvimento e aprendizagem.

\section{METODOLOGIA}

Este trabalho foi realizado por meio de pesquisa documental e bibliográfica e da aplicação de questionário a uma amostragem de alunos que cursam o Pronatec no sistema $\mathrm{S}$ - Senai e Senac. Portanto, a análise das avaliações, através da aplicação de questionários a um grupo de alunos que cursam o Pronatec, proporciona à pesquisa, um caráter avaliativo na mensuração dos dados levantados.

A avaliação é construída através de diversos olhares, por diversos ângulos do conhecimento científico. Vieira (1996, p. 15) menciona que "[...] nenhuma ciência brota do cérebro de fundadores. Ela resulta da investigação realizada por muitos estudiosos, sobre problemas que aparecem em determinadas condições históricas".

Como citado, a aplicação de questionário aos alunos que cursam os variados cursos ofertados pelo sistema $S$, reforçam a importância da escolha do método certo para alcançar os objetivos de análise do programa, do nível de satisfação dos alunos como as dificuldades encontradas pelos mesmos durante o curso. A análise e avaliação dos dados deste estudo oportuniza a avaliação da qualidade dos cursos ofertados, a maior dificuldade encontrada pelos alunos durante o curso e suas expectativas após realização do mesmo, como inserção no mercado de trabalho, facilidades e dificuldades no confronto entre teoria e prática. 


\section{ANÁLISE E DISCUSSÃO}

\subsection{DADOS COLETADOS}

O Pronatec foi criado em 26 de outubros de 2011 e entre outras intenções, busca garantir a formação e/ou qualificação técnica de profissionais que necessitam ingressar ou reingressar no mercado de trabalho, atendendo a uma necessidade social que é a geração de mão de obra qualificada para as atuais exigências do mercado de trabalho.

No mesmo ano iniciou suas atividades em parceria com a Rede Pública de Educação, com as Secretarias de Educação do Estado que passou a ser chamada de instituição demandante e o Senai e Senac, instituições do sistema S, sendo denominados ofertantes. Inicialmente, ofertaram os primeiros cursos, sendo eles: técnico em vendas, técnico em guia de turismo, técnico em eletrotécnica, técnico em biotecnologia, técnico em mecatrônica, técnico em mecânica, técnico em logística e técnico em vestuário. Na modalidade Formação Inicial Continuada - FIC a oferta foi para os cursos de Moda, Programação na Web, Recepcionista, administração de redes, auxiliar administrativo, eletricista, instalador predial de baixa tensão, eletricista de automóveis, reparador de circuitos eletrônicos, mecânico de manutenção de motocicletas, aplicador de revestimento cerâmico, pedreiro de alvenaria, pintor de obras.

A partir destas informações foi aplicado um questionário aos alunos regularmente matriculados nos cursos Pronatec na modalidade Concomitante. A escolha desta modalidade de curso está vinculada ao fato deles estarem mais intimamente ligado aos alunos que cursam a partir do $2^{\circ}$ ano do Ensino Médio. Os cursos não foram o foco da pesquisa e sim o nível de satisfação dos alunos conforme objetivos propostos. Segue análise dos dados.

\subsection{DISCUSSÃO}

Segundo a pesquisa de Jannuzzi (2016), o Pronatec como outros programas sociais precisa ser avaliado para que sua implementação atinja os objetivos que foram 
almejados inicialmente. Neste sentido, analisando a complexidade da efetivação do Pronatec, se passa a discutir os resultados alcançados nesta estudo objetivando aos gestores formas de potencializar o sucesso do programa.

A construção de indicadores para formulação, monitoração e avaliação - ou simplesmente, em sentido lato, para avaliação de políticas e programas não é uma tarefa trivial. Trata-se de um empreendimento técnico-científico que requer tempo, esforço metodológico e refinamentos sucessivos do conceito, do processo investigado ou do fenômeno social em questão, (JANNUZZI, 2016, p. 627).

O autor esclarece que muitas vezes a falta de uma análise do programa é por falta de clareza sobre o conceito do que é o programa, do seu processo de formulação, implementação e avaliação do impacto desta política na parcela social que se pretende atingir. Os programas políticos visam melhorar as condições de vida dos cidadãos envolvidos, promover a justiça social de acesso aos serviços, entre outros objetivos. No caso do Pronatec e sendo a educação o foco desta política de governo, é necessário que os gestores públicos tenham a competência necessária para o sucesso do mesmo, independente se são instituições de ensino públicas ou privadas. Analisar a eficiência deste programa e sua aceitação pelo público-alvo é fundamental quando se pretende manter e aprimorar o programa.

Jannuzzi (2016) relata que para uma avaliação de uma política pública governamental como o Pronatec requer uma avaliação sistêmica e que devem ter como ponto de partida uma pesquisa diagnóstica do público-alvo, análise da adequação da oferta em relação a demanda locais e regionais, análise da capacidade técnica das instituições ofertantes do programa, registros das situações de ensino/ aprendizagem em sala de aula, processos de informações sobre os cursos, acompanhamento pedagógico e outros. A análise da satisfação do público envolvido, sua empregabilidade pós curso também oportunizam mensurar o programa e a política a curto e longo prazo. Dentro deste contexto é que passamos para análise dos dados coletados na pesquisa.

No primeiro item de análise que reflete as "expectativas e satisfação dos alunos com o curso e conteúdo dos mesmos", é possível verificar que os alunos 
possuem conhecimento sobre o curso ofertado e que os mesmos estão dentro das expectativas projetadas no início do curso. A satisfação do aluno em relação ao curso também foi positiva, como também os conteúdos apresentados em suas diversas disciplinas.

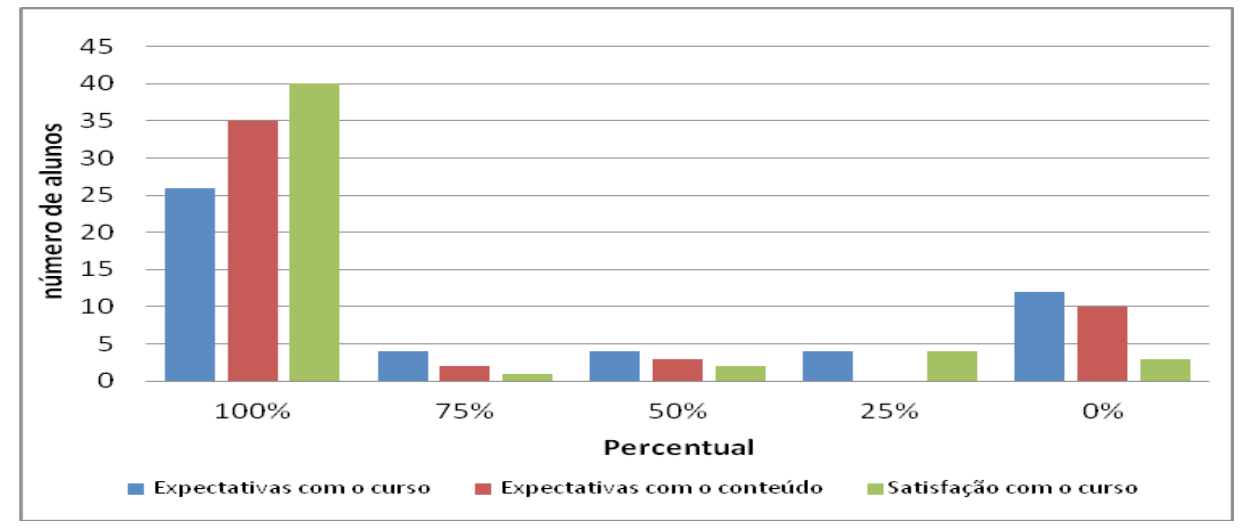

Gráfico 1. Expectativas e satisfação dos alunos com o curso e conteúdo

Como descrito no gráfico a seguir, é observado que os alunos vislumbram na educação um caminho, um sucesso que deve ser visto com dedicação e comprometimento. O período atual de avaliação da educação brasileira questiona-se muito a qualidade ofertada no processo formativo. Contudo, verifica-se conforme o gráfico a seguir, que os alunos advindos de diversas instituições públicas, conseguem e dominam o conteúdo exigido no curso. Este é um ponto positivo detectado na pesquisa. 


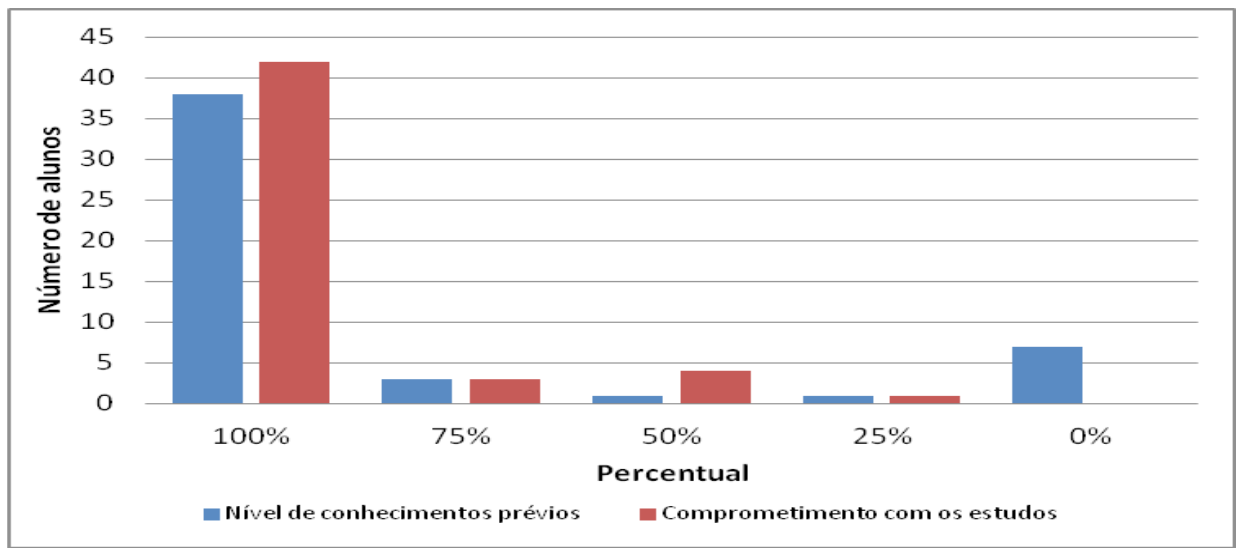

Gráfico 1. Nível de Conhecimento Prévio e Comprometimento com os estudos

Observa-se uma avaliação positiva das instituições ofertantes, como sendo de boa qualidade e que estão trabalhando para oportunizar o aprendizado de qualidade aos alunos. Percebe-se que o curso exige conhecimentos e estudos constantes dos alunos e que o Pronatec e o Ensino Médio podem ser ofertados na forma concomitante, pois um não atrapalha o desenvolvimento do outro ou a qualidade do aprendizado.

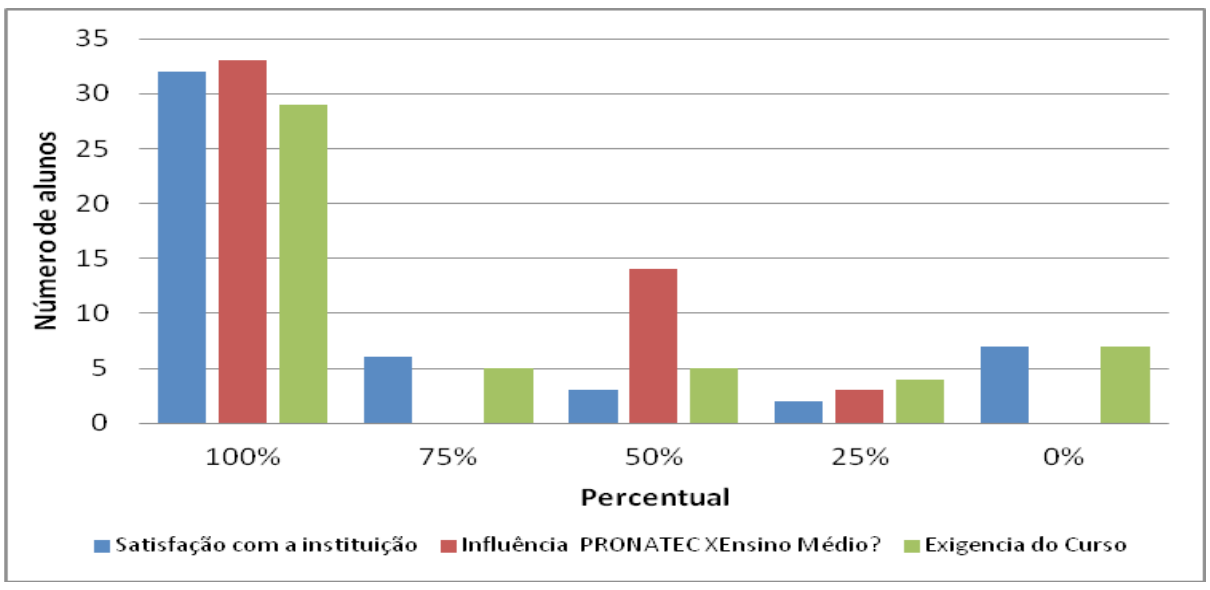

Gráfico 3. Relação teoria e prática e expectativas futuras 
Quanto à empregabilidade e expectativas futuras com o curso, verifica-se que os alunos, sendo o público adolescente do Ensino Médio, apresentam certa desconfiança e incerteza sobre a equação estudos = futuro promissor. Percebese que eles acreditam nos estudos e não necessariamente no futuro profissional e econômico que ele possa trazer pelo Pronatec. Os quadros abaixo representam esta situação.

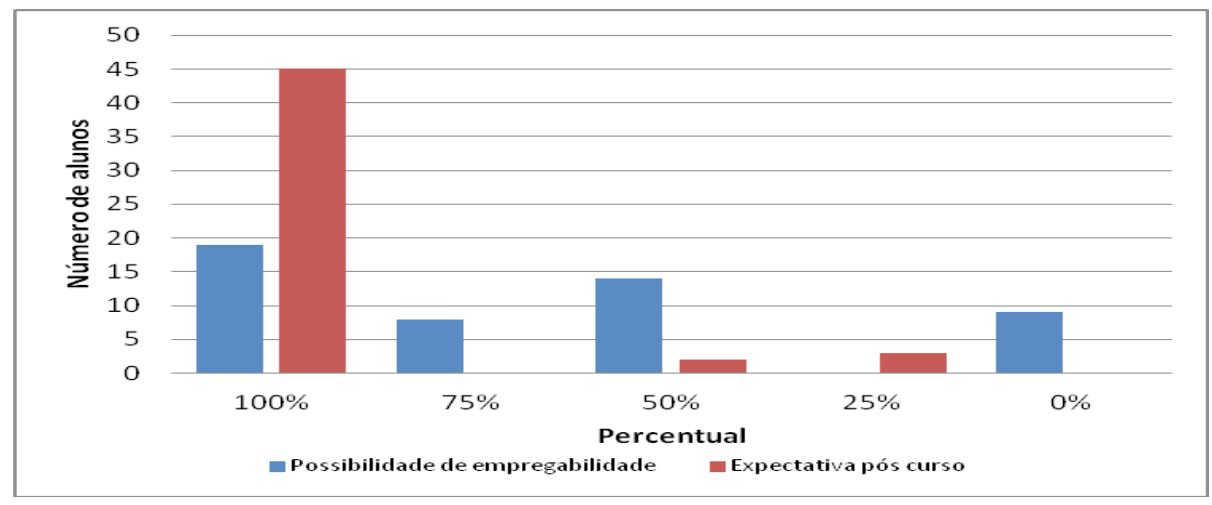

Gráfico 4. Empregabilidade pré e pós Pronatec

A pesquisa contemplou uma análise singela de interesses, comportamentos, visão de futuro, credibilidade das instituições, relação Pronatec e Ensino Médio e previsão de futuro pós-curso. Este trabalho não contemplou os casos de evasão que ocorrem nos cursos, pelos mais diversos motivos e condicionantes, porém é questão para um próximo estudo.

\section{CONCLUSÃO}

Ao analisar o surgimento e desenvolvimento do Pronatec no Paraná e especificamente na cidade de Maringá, é identificado que se trata de uma política pública governamental, tendo por objetivo agregar e desenvolver condições de fomento de mão de obra para suprir os interesses socioeconômicos e políticos, articulados com os interesses de fomento da indústria, comercio e serviços. Como 
cita Deitos, Lara e Zanardini (2015), estes interesses empresarias levam o aluno a "internalizar" que sua ascensão profissional ocorre devido a sua ineficiência funcional e profissional de qualificação. Estes argumentos levam o jovem e adultos trabalhadores à compreensão de que lhes faltam condições para sua entrada e permanência no mercado de trabalho aumentando a expectativa social na escola como promotora de "qualificação e empregabilidade ou a geradora de supostas e novas competências e qualificações para o acesso aos mesmos,"(DEITOS; LARA; ZANARDINI, 2015, p. 997).

O Pronatec tem sido desenvolvido em Maringá com extrema competência e qualidade pelas instituições ofertantes do Sistema S. Apesar de ser uma política pública, voltada para a solução rápida de questões sociais relacionadas ao mercado de trabalho e a empregabilidade nas diversas instancias, também é um programa que deve ser aproveitado para incentivar o aluno para a busca de uma carreira profissional e que oportuniza condições de estudo aliada a qualificação.

$\mathrm{Na}$ esfera educacional, deve ser compreendido como um mecanismo de fomentar a permanência do aluno vinculado a instituições de ensino e desenvolvimento da Educação Profissional. Outro fator importante produzido por esta oferta de Pronatec é que o público-alvo que são os jovens do Ensino Médio permanecem o dia todo nas escolas públicas e parceiras, evitando sua ociosidade e perigos da vida moderna. Percebe-se que estando ocupados durante todo o dia, acabam tendo pouco tempo para as atividades desinteressantes que a vida oferece. Avaliando seu nível de interesse e satisfação, conclui-se que o Pronatec poderá, durante um pequeno período de tempo, abrir oportunidades aos jovens que cursam o Ensino Médio, como também promover a empregabilidade para os mesmos.

O Pronatec não é uma Política Pública voltada exclusivamente para a educação como seria necessário que fosse. Funciona como paliativo para problemas sociais e estruturais maiores que perpassam pela vontade política dos governantes e da organização social da comunidade. Contudo, soluções como este programa serão sempre perseguidos com objetivo de minimizar e não resolver a falta de qualidade na educação pública do Brasil. 


\section{REFERÊNCIAS}

BRASIL. Ministério da Educação. Secretaria da Educação Média e Tecnológica. Educação Profissional: Legislação Básica, s/d.

BRASIL, Lei 12.513/2012. PRONATEC - Programa Nacional de Acesso ao Ensino Técnico e Emprego.

BRASIL MEC. Portal PRONATEC. Disponível em: < http://pronatec.mec.gov.br/ institucional-90037/objetivos-e-iniciativas > . Acesso em: 02 de Dez. 2018.

DEITOS, R. A.; LARA, A. M. de B.; ZANARDINI, I. M. S. Política de educação profissional no Brasil: aspectos socioeconômicos e ideológicos para a implantação do Pronatec. Educ. Soc., Campinas, v. 36, n. 133, p. 985-1001, dez. 2015. Disponível em: < http://www.scielo.br/scielo.php?script=sci_ arttext\&pid $=$ S0101-73302015000400985\&lng $=$ en\&nrm $=$ iso $>$. Acesso em:

02 Dec. 2018.

FRIGOTTO, G. C. M. (Org.). A experiência do trabalho e a educação básica. Rio de Janeiro: Lamparina, 2010.

JANNUZZI, P. M. Indicadores para avaliação sistêmica de programas sociais: o caso PRONATEC. Est. Aval. Educ., São Paulo, v. 27, n. 66, p. 624-661, set./dez. 2016. Disponível em: <http://publicacoes.fcc.org.br/ojs/index.php/eae/article/ view/4168>. Acesso em: 02 dez. 2018.

LAKATOS, E.M; MARCONI, M. A. Fundamentos de metodologia cientifica. 3. ed. São Paulo: Atlas, 1991.

LIMA, M.; PACHECO, Z. S. T. A. As políticas públicas e o direito à educação: programa nacional de acesso ao ensino técnico e emprego versus plano nacional de educação. Educ. Soc., Campinas, v. 38, n. 139, p. 489-504, jun. 2017. Disponível em: <http://www.scielo.br/scielo.php?script=sci_arttext\&pid=S010173302017000200489\&lng $=$ en\&nrm $=$ iso $>$. Acesso em: 02 dez. 2018.

LUKÄCS, G. As bases ontológicas do pensamento e da atividade do homem. Temas de Ciências Humanas, v. 4, p. 1-18, 1978. 
PARANÁ. SEED. Superintendência da Educação. Departamento de Educação e Trabalho. $\mathbf{O}$ ensino médio integrado à educação profissional: concepções e construções a partir da implantação na Rede Pública Estadual do Paraná/Secretaria de Estado da Educação. Superintendência da Educação. Departamento de Educação Profissional. Curitiba: SEED/PR, 2008.

PARANÁ. SEED. Diretrizes da Educação Profissional: fundamentos políticos e pedagógicos, Curitiba, PR, 2006. Disponível em: < http://www.educadores.diaadia. pr.gov.br/arquivos/File/diretrizes/diretriz_educacao_profissional.pdf $>$. Acesso em: 02 dez. 2018.

PARANÁ. SEED. Deliberação 05/2013, de 10 de dezembro de 2013/CEE. Deliberação sobre Educação Profissional Técnica de Nível Médio. Revogação das Deliberações 09/06 e 04/08.

PARANÁ. SEED. Deliberação 03/2013, de 4 de outubro de 2013/CEE.

VIEIRA, E. Sociologia da educação: reproduzir e transformar. São Paulo: FDT, 1996, p. 12-41.

Recebido em: 06/09/2018

Aceito em: 10/12/2018 